\title{
Assessment of the toll-like receptor 4 Asp299Gly, Thr399lle and interleukin-8 -25 I polymorphisms in the risk for the development of distal gastric cancer
}

\author{
Elvira Garza-Gonzalez ${ }^{1}$, Francisco J Bosques-Padilla², Sandra I Mendoza- \\ Ibarra ${ }^{1}$, Juan P Flores-Gutierrez ${ }^{3}$, Hector J Maldonado-Garza ${ }^{2}$ and \\ Guillermo I Perez-Perez*4
}

\begin{abstract}
Address: ${ }^{1}$ Departamento de Microbiología, Facultad de Medicina, Universidad Autónoma de Nuevo León, Monterrey, Mexico, ${ }^{2}$ Servicio de Gastroenterología, Hospital Universitario "Dr. José Eleuterio González", Universidad Autónoma de Nuevo León, Monterrey, Mexico, ${ }^{3}$ Laboratorio de Anatomía Patológica, Hospital Universitario "Dr. José Eleuterio González" Universidad Autónoma de Nuevo León, Monterrey, Mexico and ${ }^{4}$ Departments of Medicine and Microbiology, New York University School of Medicine, New York, USA

Email: Elvira Garza-Gonzalez - elvira_garza_gzz@yahoo.com; Francisco J Bosques-Padilla - fbosques58@hotmail.com; Sandra I MendozaIbarra - qfb_sandra_mendoza@yahoo.com; Juan P Flores-Gutierrez - jufloresmx@hotmail.com; Hector J Maldonado-

Garza - dr.hectormaldonadog@gmail.com; Guillermo I Perez-Perez* - perezg02@med.nyu.edu

* Corresponding author
\end{abstract}

Published: 26 April 2007

BMC Cancer 2007, 7:70 doi:10.1186/147/-2407-7-70

This article is available from: http://www.biomedcentral.com/I47I-2407/7/70

(C) 2007 Garza-Gonzalez et al; licensee BioMed Central Ltd.

This is an Open Access article distributed under the terms of the Creative Commons Attribution License (http://creativecommons.org/licenses/by/2.0), which permits unrestricted use, distribution, and reproduction in any medium, provided the original work is properly cited.
Received: 12 October 2006 Accepted: 26 April 2007

\begin{abstract}
Background: The intensity of the inflammation induced by Helicobacter pylori colonization is associated with the development of distal gastric cancer (GC). The host response to $H$. pylori has been related to genetic polymorphisms that influence both innate and adaptive immune responses.

Our aim was to investigate whether the presence of the TLR4 Asp299Gly, TLR4 Thr399Ile and IL-825 I A/T polymorphisms had any influence in the development of distal GC in a Mexican population.

Methods: We studied 337 patients that were divided in two groups: 78 patients with histologically confirmed distal GC and 259 non-cancer controls. The presence of $H$. pylori in the control population was defined by positive results of at least two of four diagnostic tests: serology, histology, rapid urease test and culture. Human DNA was purified and genotyped for TLR4 Asp299Gly polymorphism by pyrosequencing, for TLR4 Thr399lle by PCR-RFLP and for IL8-25I by the amplification refractory mutation system (ARMS)-PCR.

Results: The non-cancer control group was found to be in Hardy-Weinberg equilibrium at the polymorphic loci studied (chi-square ${ }_{\mathrm{H}-\mathrm{W}}=0.58$ for IL8-25I, 0.42 for TLR4 Asp299Gly and 0.17 for TLR4 Thr399/le). The frequencies of mutated alleles (homozygous plus heterozygous) were compared between cases and controls. We found no significant difference for TLR4-Asp299Gly [the 7.7\% of distal GC patients and $7.7 \%$ non-cancer controls $(p=0.82)$ ] and for TLR4 Thr399lle [the $1.3 \%$ of GC patients and the $5 \%$ of the control population ( $p=0.2)$ ]. In contrast, for IL-8-25I A/T, $80.77 \%$ of the GC patients and $66.4 \%$ in the control group age and gender matched had at least one copy of mutated allele $(\mathrm{OR}=2.12,95 \% \mathrm{Cl}=1 . \mathrm{I}-4.2)(\mathrm{p}=0.023)$.
\end{abstract}

Conclusion: This study showed that the IL8-25I*A allele could be related to the development of distal gastric cancer in this Mexican population. 


\section{Background}

Helicobacter pylori almost exclusively colonize the mucous layer of the human stomach and reside in the host for years, decades or maybe lifelong. In approximately $10 \%$ of cases, the organism is associated with diverse clinical outcomes, including non-ulcer dyspepsia, peptic ulcer disease, and distal gastric cancer [1].

Both host and environmental factors have been associated with this clinical diversity. Host factors are mainly related to the recognition of the bacteria by the immune system and variation in the level of cytokine response $[2,3]$.

Recognition of pathogens is mediated by a set of germline-encoded receptors that are referred to as pattern-recognition receptors (PRRs). These receptors recognize conserved molecular patterns, which are shared by large groups of microorganisms. An important PRR is Toll-like receptor 4 (TLR4), a transmembrane receptor that recognizes a range of ligands, including lipopolysaccharide (LPS), which is found in the cell wall of Gram-negative bacteria like H. pylori [3]. Two single nucleotide polymorphisms (SNPs) in the TLR4 gene, Asp-299 $\rightarrow$ Gly and Thr$399 \rightarrow$ Ile transitions, have been shown to lead to hyporesponsiveness to LPS, reduced epithelial TLR4 density and reduced inflammatory cytokine response to LPS [4]. Furthermore, genetic variants of cytokines are also critical for the inflammatory response, and several genes from different pathways have been associated with gastric cancer, including interleukin (IL)-1B, TNF, $I L-10$ and $I L-8$ [5-7].

IL-8 cytokine functions as a potent chemoattractant for neutrophils and lymphocytes. It has been reported that IL8 levels increased 10-fold in gastric cancer specimens when compared with normal gastric tissues. A well-characterized SNP T/A in the -251 locus has been described and associated with higher IL- 8 production and several diseases [8-11].

Our aim was to determine whether the TLR4 Asp299Gly, TLR4 Thr399Ile and the IL8-251 A/T polymorphisms are associated with distal gastric cancer in a well-defined Mexican population.

\section{Methods}

\section{Patient population}

We studied 78 unrelated patients with histologically confirmed distal GC (mean age $=58.6 \mathrm{y}$, median age $=60$, age range: $22-84, \mathrm{~F}: \mathrm{M}=0.56$ ). We also studied 259 patients with no histological evidence of GC (mean age $=57.1 \mathrm{y}$, median age $=54$, age range $=18-92, \mathrm{~F}: \mathrm{M}=1.17)$. This population has been described previously [7]. All patients were enrolled at the Hospital Universitario "Dr. José Eleuterio González", Universidad Autónoma de Nuevo León.
The local ethical committee approved the study and written informed consent was obtained from all subjects.

\section{Histopathological examinations}

From all control patients, eight biopsy specimens were obtained for histological evaluation, two from the lesser curvature, two from the greater curvature, two from the incisura angularis, and two from the prepyloric region. From patients with distal GC, at least 8 biopsies were obtained from the tumor for histological evaluation. Biopsies from cases and controls were fixed, paraffin embedded and stained with hematoxilin-eosin. An experienced pathologist examined all the histological slides.

\section{H. pylori status}

The H. pylori status of the control population was determined by histology, the rapid urease test (RUT), serology and culture. For the RUT, an antral biopsy was analyzed by a validated non-commercial test [12]. The biopsy was placed in a test vial, incubated at $37^{\circ} \mathrm{C}$ and read within 24 $\mathrm{h}$. A color change from orange to magenta indicated a positive result. For serology, an enzyme-linked immunosorbent assay (ELISA) was used to demonstrate the presence of IgG antibodies as previously described [13].

Culture was performed on two corpus and two antrum biopsies by standard methods. Biopsies were placed in $10 \%$ blood agar (Becton Dickinson, Cockeysville, MD) and incubated at $37^{\circ} \mathrm{C}$ for at least one week under microaerobic conditions. Strains were identified by Gram staining, oxidase, catalase and urease tests.

Control patients were considered $H$. pylori infected when at least two of the diagnostic tests were positive.

The prevalence of $H$. pylori infection in gastric cancer patients was determined by the result of histology only.

\section{Genotyping}

Genomic DNA was extracted from peripheral blood by the phenol-chloroform-isoamilic alcohol and precipitation with ethanol method. An amplification refractory mutation system (ARMS)-PCR method was used to genotype the IL8-251 polymorphism as described previously [14].

The TLR4 Thr399Ile polymorphism was determined by PCR-RFLP [15] and the TLR4 Asp299Gly polymorphism was determined by a pyrosequencing method designed for this study. Initially, a PCR was performed with the primers F-GAT TAG CAT ACT TAG ACT ACT ACC TCC ATG and R-CCC TTT CAA TAG TCA CAC TCA CCA GG with the reverse primer biotinylated. The PCR conditions were: $94^{\circ} \mathrm{C}$ for $5 \mathrm{~min}$ and 40 cycles of $94^{\circ} \mathrm{C}, 59^{\circ} \mathrm{C}$ and $72^{\circ} \mathrm{C}$ for $30 \mathrm{~s}$ each, and a final extension at $72^{\circ} \mathrm{C}$ for 5 
min. For pyrosequencing, biotinylated PCR templates were immobilized on streptavidin-coated paramagnetic Sepahrose beads in binding buffer. The bead-template complexes were washed by submersion in $70 \%$ alcohol and $0.5 \mathrm{M} \mathrm{NaOH}$ and then added to $45 \mu \mathrm{l}$ of annealing buffer containing $15 \mathrm{pmol}$ of the sequencing primer $5^{5}$ CAT ACT TAG ACT ACT ACC TC 3'. Annealing took place at $80^{\circ} \mathrm{C}$ for $2 \mathrm{~min}$. Real-time pyrosequencing was performed in an automated 96-well pyrosequencer PSQ SNP 96 (Pyrosequencing AB, Uppsala, Sweden) using enzymes and substrates recommended by the manufacturer.

\section{Statistical analysis}

Hardy-Weinberg equilibrium of alleles at individual loci was assessed by chi-square statistics. Statistically significant differences were determined by Student's $t$ test, chisquare or Fisher exact test, two tailed. A probability (p) value $<0.05$ was considered as statistically significant. Odds ratios (OR) with 95\% confidence intervals (CIs) were computed using the Epi-Info 2000 software (Center for Disease Control and Prevention, Atlanta, Ga.). Three analyses were performed, one in which all cases and controls were included, a second in which cases were compared only with $H$. pylori + controls and a third analysis in which the population-based controls were matched by 5year age group and gender with the cancer cases.

\section{Results}

\section{Study groups characteristics and $\mathbf{H}$. pylori status}

The distribution of genotypes according to histological findings is shown on Table 1.

The genotype frequencies at the individual loci studied were in Hardy-Weinberg equilibrium, with non-significant chi-square values $(0.58$ for IL8-251, 0.42 for TLR4 Asp299Gly and 0.17 for the TLR4 Thr399Ile). Among the control group, the $80 \%$ had chronic gastritis (Table 1), $11.2 \%$ of patients had PUD and $8.8 \%$ of patients had atrophic gastritis and/or intestinal metaplasia. The proportion of diffuse and intestinal gastric cancer was 1.2:1.

The prevalence of $H$. pylori in the control group was $73.7 \%$. This is similar to the value previously reported for this study population [16]. The prevalence of $H$. pylori among the gastric cancer patients was $53.8 \%$.

\section{Assessment of risk of IL8-25 I A/T, TLR4 Asp299Gly and TLR4 Thr399lle genotypes}

We compared all particular genotypes for IL8-251 (AA, AT and TT), for TLR4 Asp299Gly $(1,1,1,2$ and 2,2) and TLR4 Thr399Ile (1,1, 1,2 and 2,2) (Table 1). The frequency of the IL8-251 AT genotype was higher in the gastric cancer cases than in all controls, only $\mathrm{H}$. pylori positive controls and age and gender matched controls (Table 2).

\section{Assessment of risk of IL8-25 I*A, TLR4 Asp299Gly*2 and TLR4 Thr399lle*2 alleles}

We next compared the carriage of the IL8-251*A allele (homozygous plus heterozygous) for GC cases and all gastritis plus normal controls. We found an association of the $I L 8-251{ }^{*} A$ allele and the development of GC $(\mathrm{OR}=2.12$, $95 \% \mathrm{CI}=1.1-4.2, \mathrm{p}=0.023$ ) (Table 2). When we compared all gastritis plus normal controls $v$ s histological cancer types, the risks for diffuse and intestinal gastric cancer types were similar but not significant $(\mathrm{OR}=2.15, \mathrm{p}=0.08$ and $\mathrm{OR}=2.1, \mathrm{p}=0.13$ respectively) .

When we compared the gastric cancer cases with the $H$. pylori+ controls we found a similar value $(\mathrm{OR}=2.12,95 \%$ $\mathrm{CI}=1.1-4.2, \mathrm{p}=0.029)$.

Next, we compared the frequency in the gastric cancer group withage and gender matched controls and we found a stronger association (OR: $2.42,95 \% \mathrm{CI}=1.2-4.8$, $\mathrm{p}=0.0 .009$ ).

We did not find any association for TLR4 Asp299Gly*2 and TLR4 Thr399Ile* 2 hyporeactive alleles.

\section{Discussions and conclusion}

The diversity in response to the infection by $H$. pylori has been attributed to several factors. The genetically regulated immune response seems to play a crucial role in determining the intensity of damage to the host [1-3].

Several authors have described the increased production of IL-8 during $H$. pylori infection. An A/T polymorphism at the position -251 in the gene has been associated to a higher activity of this interleukin and recently, this allele has been related in two studies to the development of gastric cancer in Japanese population [10,11]. In one of those studies, the IL8-251 AA genotype held a higher risk of atrophic gastritis $(\mathrm{OR}=2.35 ; 95 \%, \mathrm{CI}=1.12-4.94)$ and gastric cancer $(\mathrm{OR}=2.22 ; 95 \% \mathrm{CI}=1.08-4.56)$ compared with the TT genotype. They studied 252 healthy controls, 215 individuals with atrophic gastritis, and 396 patients with gastric cancer. The AA and AT genotypes were significantly associated with higher levels of IL8 protein, more severe neutrophil infiltration compared with the TT genotype. In the other study, the IL- $8-251^{*}$ A allele was associated to a higher risk of gastric cancer $(\mathrm{OR}=2.1,95 \% \mathrm{CI}=$ $1.38-2.92)$. Our results showed no association between higher rates of GC and the AA genotype, but a positive association was found for the AT genotype and the carriage of at least one copy of the ${ }^{*} \mathrm{~A}$ allele (homozygous plus heterozygous). It is remarkable that the ORs value observed in our study (2.12) was quite similar to that observed in the Japanese population (2.1). 
Table I: Genotype and allele frequencies of the IL-8 25I A/T and TLR-299 and -399 loci in the non-cancer and cancer groups according to histological findings

\begin{tabular}{|c|c|c|c|c|c|c|c|c|c|c|c|c|c|}
\hline \multirow{3}{*}{ Group (n) } & \multicolumn{5}{|c|}{ IL8-25I A/T } & \multicolumn{4}{|c|}{ TLR4 Asp299Gly } & \multicolumn{4}{|c|}{ TLR4Thr399lle } \\
\hline & \multicolumn{3}{|c|}{ genotype } & \multicolumn{2}{|c|}{ allele } & \multicolumn{2}{|c|}{ genotype } & \multicolumn{2}{|c|}{ allele } & \multicolumn{2}{|c|}{ genotype } & \multicolumn{2}{|c|}{ allele } \\
\hline & AA & AT & TT & $* \mathrm{~A}$ & $* \mathrm{~T}$ & $\mathrm{I}, \mathrm{I}$ & $\mathrm{I}, 2$ & $* 1$ & $* 2$ & $\mathrm{I}, \mathrm{I}$ & 1,2 & $* 1$ & $* 2$ \\
\hline Gastritis (207) & 42 & 97 & 68 & 0.44 & 0.56 & 190 & 17 & 0.96 & 0.04 & 196 & 11 & 0.97 & 0.03 \\
\hline PUD (29) & 4 & 14 & 11 & 0.38 & 0.62 & 29 & 0 & 1 & 0 & 27 & 2 & 0.97 & 0.03 \\
\hline$A G+I M(23)$ & 5 & 10 & 8 & 0.43 & 0.57 & 20 & 3 & 0.93 & 0.07 & 23 & 0 & 1 & 0 \\
\hline Gastric cancer (78) & 16 & 47 & 15 & 0.51 & 0.49 & 72 & 6 & 0.96 & 0.04 & 77 & 1 & 0.99 & 0.01 \\
\hline diffuse type & 8 & 26 & 8 & 0.5 & 0.5 & 38 & 4 & 0.95 & 0.05 & 41 & 1 & 0.99 & 0.01 \\
\hline intestinal type & 8 & 21 & 7 & 0.51 & 0.49 & 34 & 2 & 0.97 & 0.03 & 36 & 0 & 1 & 0 \\
\hline H. pylori + (191) & 37 & 90 & 64 & 0.43 & 0.57 & 175 & 16 & 0.96 & 0.04 & 181 & 10 & 0.97 & 0.03 \\
\hline Age and gender matched $(n=189)$ & 33 & 87 & 69 & 0.4 & 0.6 & 175 & 14 & 0.96 & 0.04 & 179 & 10 & 0.97 & 0.03 \\
\hline
\end{tabular}

PUD: peptic ulcer disease; AG, atrophic gastritis; IM: intestinal metaplasia

The IL-1B-31 C/T polymorphism has been associated with the development of gastric cancer and a geographical-ethnic difference has been described for this locus, with a stronger association of the polymorphism in occidental than in oriental population. The results for the $I L-8-251 \mathrm{~A} /$ $\mathrm{T}$ polymorphism correlate with previous data presented for Japanese population, showing no trend in geographical or ethnic variation.

It is currently unresolved whether a hyporesponsive LPS signaling pathway is beneficial or detrimental to the host. Individuals with the hyporeactive TLR4 polymorphisms have shown reduced levels of circulating inflammatory cytokines, an increased risk of acute bacterial infections and a trend towards increased mortality. Other recent studies support the hypothesis that the low-functioning TLR4 polymorphisms may result in a reduced inflammatory response associated with a low-damaging infection that will promote a persistent infection [17-20]. In this study, we did not find any association between GC and TLR4 polymorphisms, suggesting they do not contribute to the development of distal gastric cancer. Both TLR4 Asp299Gly and Thr399Ile polymorphisms have been reported in linkage disequilibrium (LD) $[21,22]$, but we decided to genotype both because we did not know if they were in LD in our population.

In conclusion, our preliminary results suggest that IL8-251 is a biologically plausible disease-modifying polymorphism. If confirmed in multiple populations, as it has been in Japanese, and now Mexican groups, this polymorphic site, in conjunction with others, could be used to identify patients at greater risk for GC, who may need closer monitoring.

\section{Competing interests}

The author(s) declare that they have no competing interests.

\section{Authors' contributions}

EGG designed and coordinated the study, optimized PCR conditions, carried out molecular analysis and drafted the manuscript. SM performed PCRs analysis, JPFG performed histological examination and interpretation of results, FJBP and HJMG recruited patients and carried out endoscopies and gastric biopsies, GIPP conceived of the study, and participated in its design and coordination. All authors read and approved the final manuscript.

Table 2: Odds ratios and $95 \%$ confidence intervals for the analysis the genotypes of distal gastric cancer cases vs all non-cancer controls.

\begin{tabular}{|c|c|c|c|c|c|c|c|c|}
\hline \multirow[b]{2}{*}{ All cases vs } & \multicolumn{2}{|c|}{ IL8-25I*A } & \multicolumn{2}{|c|}{ IL8-25I AT } & \multicolumn{2}{|c|}{$T L R-299 * 2$} & \multicolumn{2}{|l|}{ TLR-399*2 } \\
\hline & OR $(95 \% \mathrm{Cl})$ & $\mathrm{P}$ & OR $(95 \% \mathrm{Cl})$ & $P$ & OR $95 \% \mathrm{Cl}$ & $P$ & OR $95 \% \mathrm{Cl}$ & $\mathrm{P}$ \\
\hline All controls $(n=259)$ & $2.12(1.1-4.2)$ & 0.023 & $1.73(1-3)$ & 0.049 & I (0.3-2.8) & .82 & $0.25(0.01-1.8)$ & 0.2 \\
\hline H. pylori + controls $(n=191)$ & $2.12(1.1-4.2)$ & 0.029 & $1.7(0.96-3)$ & 0.068 & $0.91(0.3-2.6)$ & 0.95 & $0.24(0-1.8)$ & 0.19 \\
\hline Age and gender matched controls $(n=189)$ & $2.42(1.2-4.8)$ & 0.009 & $1.78(1-3.2$ & 0.035 & $1.04(0.3-3.1)$ & 0.86 & $0.23(0-1.8)$ & 0.1 \\
\hline
\end{tabular}




\section{References}

I. Dunn BE, Cohen H, Blaser MJ: Helicobacter pylori. Clin Microbiol Rev 1997, 10:720-74I.

2. Rad R, Dossumbekova A, Neu B, Lang R, Bauer S, Saur D, Gerhard $M$, Prinz C: Cytokine gene polymorphisms influence mucosal cytokine expression, gastric inflammation, and host specific colonization during Helicobacter pylori infection. Gut 2004, 53:1082-1089.

3. Ferrero RL: Innate immune recognition of the extracellular mucosal pathogen, Helicobacter pylori. Mol Immunol 2005 , 42:879-485.

4. Schroder NW, Schumann RR: Single nucleotide polymorphisms of Toll-like receptors and susceptibility to infectious disease. Lancet Infect Dis 2005, 5:156-164.

5. Perez-Perez GI, Garza-Gonzalez E, Portal C, Olivares AZ: Role of cytokine polymorphisms in the risk of distal gastric cancer development. Cancer Epidemiol Biomarkers Prev 2005, I4:1869-|873.

6. El-Omar EM, Carrington M, Chow WH, McColl KE, Bream JH, Young HA, Herrera J, Lissowska J, Yuan CC, Rothman N, Lanyon G, Martin $M$, Fraumeni JF Jr, Rabkin CS: Interleukin-I polymorphisms associated with increased risk of gastric cancer. Nature 2000 , 404:398-402.

7. Garza-Gonzalez E, Bosques-Padilla FJ, El-Omar E, Hold G, TijerinaMenchaca R, Maldonado-Garza HJ, Perez-Perez Gl: Role of the polymorphic IL-IB, IL-IRN and TNF-A genes in distal gastric cancer in Mexico. Int / Cancer 2005, I | 4:237-24 I.

8. Camorlinga-Ponce M, Aviles-Jimenez F, Cabrera L, Hernandez-Pando $\mathrm{R}$, Munoz $\mathrm{O}$, Soza J, Torres J: Intensity of inflammation, density of colonization and interleukin-8 response in the gastric mucosa of children infected with Helicobacter pylori. Helicobacter 2003, 8:554-560.

9. Lee WP, Tai DI, Lan KH, Li AF, Hsu HC, Lin EJ, Lin YP, Sheu ML, Li CP, Chang FY, Chao Y, Yen SH, Lee SD: The -25IT allele of the interleukin-8 promoter is associated with increased risk of gastric carcinoma featuring diffuse-type histopathology in Chinese population. Clin Cancer Res 2005, I I:643 I-644I

10. Ohyauchi M, Imatani A, Yonechi M, Asano N, Miura A, lijima K, Koike $T$, Sekine $H$, Ohara $S$, Shimosegawa $T$ : The polymorphism interleukin 8 -25 I A/T influences the susceptibility of Helicobacter pylori related gastric diseases in the Japanese population. Gut 2005, 54:330-335.

II. Taguchi A, Ohmiya N, Shirai K, Mabuchi N, Itoh A, Hirooka Y, Niwa $Y$, Goto $\mathrm{H}$ : Interleukin-8 promoter polymorphism increases the risk of atrophic gastritis and gastric cancer in Japan. Cancer Epidemiol Biomarkers Prev 2005, I 4:2487-2493.

12. Flores-Orta D, Bosques-Padilla F, Gómez-Leija G, Frederick F: Comparative study of rapid urease test (Hazell test) vs CLO-test in the diagnosis of Helicobacter pylori infection. Gut 1997 4 I (Suppl 3):AI60. Published abstract

13. Perez-Perez GI, Doworkin BM, Chodos JE, Blaser MJ: Campylobacter pylori antibodies in humans. Ann Intern Med 1998 109:11-17.

14. Hull J, Ackerman $H$, Isles $K$, Usen $S$, Pinder $M$, Thomson $A$, Kwiatkowski D: Unusual haplotypic structure of IL8, a susceptibility locus for a common respiratory virus. Am J Hum Genet 2001, 69:413-419.

15. Lorenz E, Frees KL, Schwartz DA: Determination of the TLR4 genotype using allele-specific PCR. Biotechniques 2001, 3I:22-24.

16. Bosques-Padilla FJ, Tijerina-Menchaca R, Perez-Perez GI, Flores Gutiérrez JP, Garza-González E: Comparison of Helicobacter pylori prevalence in swymptomatic patients in Northeastern Mexico with the rest of the country. Its association with gastrointestinal disease. Arch Med Res 2003, 34:60-63.

17. Faber J, Meyer CU, Gemmer C, Russo A, Finn A, Murdoch C, Zenz W, Mannhalter C, Zabel BU, Schmitt HJ, Habermehl P, Zepp F, Knuf $M$ : Human toll-like receptor 4 mutations are associated with susceptibility to invasive meningococcal disease in infancy. Pediatr Infect Dis J 2006, 25:80-8I.

18. Child NJ, Yang IA, Pulletz MC, de Courcy-Golder K, Andrews AL Pappachan VJ, Holloway JW: Polymorphisms in Toll-like receptor 4 and the systemic inflammatory response syndrome. Biochem Soc Trans 2003, 31:652-653.

19. Agnese DM, Calvano JE, Hahm SJ, Coyle SM, Corbett SA, Calvano SE, Lowry SF: Human toll-like receptor 4 mutations but not CD I 4 polymorphisms are associated with an increased risk of gram-negative infections. J Infect Dis 2002, 186:1522-1525.

20. Lorenz E, Mira JP, Frees KL, Schwartz DA: Relevance of mutations in the TLR4 receptor in patients with gram-negative septic shock. Arch Intern Med 2002, 162:1028-1032.

2I. Lamb R, Zeggini E, Thomson W, Donn R: Toll-like receptor 4 gene polymorphisms and susceptibility to juvenile idiopathic arthritis. Ann Rheum Dis 2005, 64:767-769.

22. Lorenz E, Hallman M, Marttila R, Haataja R, Schwartz DA: Association between the Asp299Gly polymorphisms in the Toll-like receptor 4 and premature births in the Finnish population. Pediatr Res 2002, 52:373-376.

\section{Pre-publication history}

The pre-publication history for this paper can be accessed here:

http://www.biomedcentral.com/1471-2407/7/70/prepub
Publish with Bio Med Central and every scientist can read your work free of charge

"BioMed Central will be the most significant development for disseminating the results of biomedical research in our lifetime. "

Sir Paul Nurse, Cancer Research UK

Your research papers will be:

- available free of charge to the entire biomedical community

- peer reviewed and published immediately upon acceptance

- cited in PubMed and archived on PubMed Central

- yours - you keep the copyright 